University of Nebraska - Lincoln

DigitalCommons@University of Nebraska - Lincoln

$7-1-2004$

\title{
The Effect of Transition Metal Additions on the Microstructure and Properties of Nanocomposite Pr-Fe-B Permanent Magnets
}

Jeffrey E. Shield

University of Nebraska - Lincoln, jshield@unl.edu

Yi Liu

University of Nebraska-Lincoln, yliu@unl.edu

R. Marr

University of Nebraska - Lincoln

Z. Chen

Magnequench Technology Center, zchen@mqii.com

Baomin $\mathrm{Ma}$

Magnequench Technology Center, baominma@mqii.com

Follow this and additional works at: https://digitalcommons.unl.edu/mrsecfacpubs

Part of the Materials Science and Engineering Commons

Shield, Jeffrey E.; Liu, Yi; Marr, R.; Chen, Z.; and Ma, Baomin, "The Effect of Transition Metal Additions on the Microstructure and Properties of Nanocomposite Pr-Fe-B Permanent Magnets" (2004). Faculty Publications: Materials Research Science and Engineering Center. 22.

https://digitalcommons.unl.edu/mrsecfacpubs/22

This Article is brought to you for free and open access by the Materials Research Science and Engineering Center at DigitalCommons@University of Nebraska - Lincoln. It has been accepted for inclusion in Faculty Publications: Materials Research Science and Engineering Center by an authorized administrator of DigitalCommons@University of Nebraska - Lincoln. 


\title{
The Effect of Transition Metal Additions on the Microstructure and Properties of Nanocomposite Pr-Fe-B Permanent Magnets
}

\author{
J. E. Shield, Y. Liu, R. Marr, Z. Chen, and B. M. Ma
}

\begin{abstract}
Permanent magnets with the general composition $\operatorname{Pr}_{9}\left(\mathrm{Fe}_{0.95} \mathrm{Co}_{0.05}\right)_{85.5} \mathrm{M}_{0.5} \mathrm{~B}_{5}$, where $\mathrm{M}$ denotes a transition metal, have been produced by melt spinning. The effect on the microstructure and magnetic properties of eight different alloying elements has been examined. The grain size and distribution have been correlated to the maximum energy product obtained. The grain size of the $\operatorname{Pr}_{9}\left(\mathrm{Fe}_{0.95} \mathrm{Co}_{0.05}\right)_{85.5} \mathrm{~B}_{5}$ control alloy was determined to be $17.5 \mathrm{~nm}$, and it was found that the grain size was not significantly reduced compared to the control alloy by any of the additions. However, some additions resulted in significant increases in grain size, notably $\mathrm{Cu}, \mathrm{Ti}$, and $\mathrm{Cr}$, which had grain sizes between 26 and $36 \mathrm{~nm}$, and an increase in the grain size distribution. The increase in grain size resulted in a loss in hysteretic squareness, leading to reduced energy products in these alloys. In other alloys, fine grain size did not always correlate to improved maximum energy products. For example, the Mo-added alloy had the finest grain size but a decreased maximum energy product, likely due to solute segregation to grain boundaries that inhibited intergranular exchange interactions. In general, Group VB additions had a more positive effect on the microstructure and magnetic properties than did other alloying additions. This paper will summarize the overall effects of the additions on the microstructures and magnetic properties, enabling further alloy design efforts in nanocomposite alloy systems.
\end{abstract}

Index Terms-Exchange-coupling, grain refinement, permanent magnet, $\mathrm{R}_{2} \mathrm{Fe}_{14} \mathrm{~B} / \alpha-\mathrm{Fe}$ nanocomposite.

\section{INTRODUCTION}

$\mathbf{N}$ ANOCOMPOSITE exchange-spring permanent magnets, particularly those based in the rare earth-iron-boron system, have generated a significant amount of attention in the last ten years. These materials possess high remanent ratios arising from intergranular exchange interactions, resulting in energy products surpassing single-phase, noninteracting permanent magnet materials. As a result, there is a strong desire to further improve the materials.

Nanocomposite permanent magnets require nanostructured grain sizes, especially for the soft magnetic phase. As a result, great effort to promote the formation of grains on the order of

Manuscript received October 15, 2003. This work was supported in part by the State of Nebraska under from the Nebraska Research Initiative grant.

J. E. Shield is with the Department of Mechanical Engineering, University of Nebraska, Lincoln, NE 68588 USA (e-mail: jshield2@unl.edu).

Y. Liu is with the Center for Materials Research and Analysis, the University of Nebraska, Lincoln, NE 68588 USA (e-mail: yliu@unlserve.unl.edu).

R. Marr was with the Department of Mechanical Engineering, University of Nebraska, Lincoln, NE 68588 USA.

Z. Chen and B. M. are with Magnequench Technology Center (e-mail: zchen@mqii.com; baominma@mqii.com).

Digital Object Identifier 10.1109/TMAG.2004.832110
10-20 $\mathrm{nm}$ has been made. The direct formation of nanoscale grains from the melt is possible during melt spinning. However, it is difficult to produce a suitably homogeneous structure, and oftentimes the resulting grain size is too coarse. As a result, numerous efforts have concentrated on refining the grain size via alloying additions such as $\mathrm{Nb}, \mathrm{Ga}, \mathrm{La}$, and $\mathrm{TiC}$ [1]-[7] to promote the formation of favorable nanostructures, especially with respect to scale and homogeneity.

In this paper, we have examined eight microalloying agents as to their effect on the nanostructure and magnetic properties of $\mathrm{Pr}-\mathrm{Fe}(\mathrm{Co})-\mathrm{B}$ nanocomposite permanent magnets.

\section{EXPERIMENTAL PRODEDURES}

Alloys with the general composition $\operatorname{Pr}_{9}\left(\mathrm{Fe}_{0.95} \mathrm{Co}_{0.05}\right)_{85.5}$ $\mathrm{M}_{0.5} \mathrm{~B}_{5}$, where $\mathrm{M}$ denotes a transition metal, were arc melted from high-purity elemental constituents. The arc-melted ingots were then melt spun at a tangential wheel speed of $15-30 \mathrm{~m} / \mathrm{s}$ in an Ar atmosphere. The resulting alloys were characterized by SQUID magnetometry at $300 \mathrm{~K}$ utilizing a quantum design PPMS and vibrating sample magnetometry, and transmission electron microscopy (TEM) using a JEOL2010. Samples for TEM were made by mounting the melt-spun ribbon on a $\mathrm{Cu}$ oval, and ion milling to perforation using a Gatan Duomill or PIPS at $4.5 \mathrm{kV}$. Grain size measurements were conducted by measuring 50-100 grains; measurements were taken along two axes of each grain, and the average of these two measurements was taken as that grain's size. This is preferable to the line intercept technique because the large number of out of contrast (or minimally contrasted) grains makes it difficult to ensure accurate count of the grain boundary intercepts. Grains of the 2-14-1 and $\alpha$-Fe phases were not distinguished in this paper. The grain size distribution was determined for each sample, which was then fitted using a Gaussian distribution function. The average and half width at half maximum were obtained from this Gaussian fit.

\section{RESUlTS AND DISCUSSION}

TEMs for three samples are shown in Fig. 1. Shown are the control (no $\mathrm{M}$ ) and $\mathrm{M}=\mathrm{Nb}$ and $\mathrm{Cu}$. Table I displays grain size averages and the half-width at half maximum (HWHM) obtained from Gaussian fits to the histograms for each sample (a typical histogram is shown in Fig. 2). The half-width is used as a reflection of a sample's uniformity; higher half widths reveal a broader grain size distribution. 

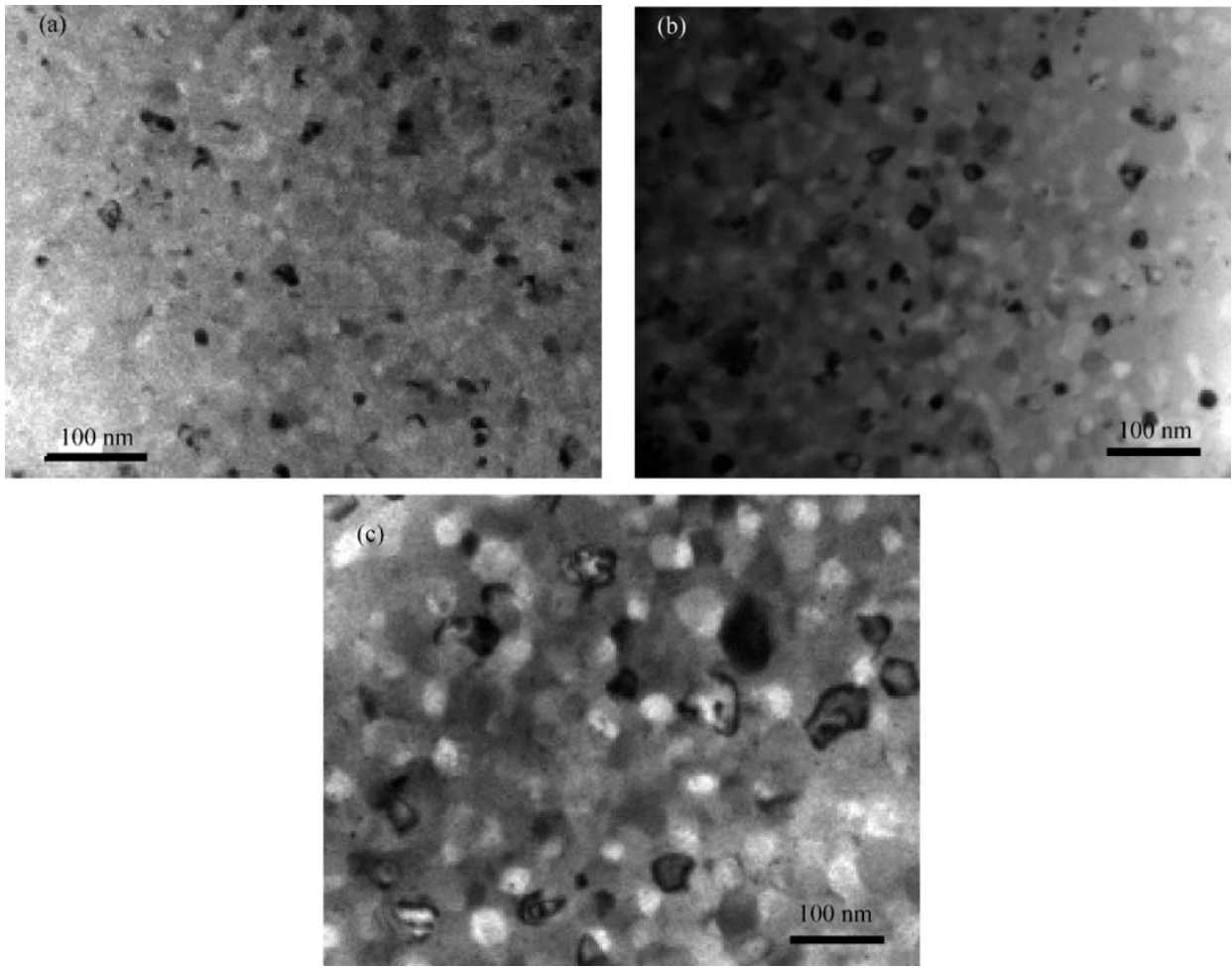

Fig. 1. TEM of (a) the control (no M), (b) $\mathrm{M}=\mathrm{Nb}$, and (c) $\mathrm{M}=\mathrm{Cu}$.

TABLE I

GRain Size, Half-Width at HaLF MaXimum (HWHM) OF THE GaUsSian Distributions, AND MAGNeTIC PROPERTIES OF THE $\mathrm{Pr}-\mathrm{Fe}(\mathrm{Co})$-B Nanocomposite Permanent MAgnets With VARIOUS MiCROALLOYING ADDITIONS

\begin{tabular}{cccccc}
\hline $\begin{array}{c}\text { Alloying } \\
\text { Element }\end{array}$ & $\begin{array}{c}\text { Avg. } \\
\text { Grain } \\
\text { Size } \\
(\mathrm{nm})\end{array}$ & $\begin{array}{c}\mathrm{HWHM} \\
(\mathrm{nm})\end{array}$ & $\begin{array}{c}(\mathrm{BH})_{\max } \\
(\mathrm{MGOe}\end{array}$ & $\begin{array}{c}\mathrm{i}_{\mathrm{i}} \mathrm{H}_{\mathrm{c}} \\
(\mathrm{kOe})\end{array}$ & $\begin{array}{c}\mathrm{T}_{\mathrm{c}} \\
\left({ }^{\circ} \mathrm{C}\right)\end{array}$ \\
\hline-- & 17.5 & 6.1 & 15.4 & 6.4 & 349 \\
$\mathrm{Nb}$ & 17.8 & 12.8 & 16.1 & 7.0 & 346 \\
$\mathrm{Zr}$ & 23.2 & 11.5 & 15.9 & 6.6 & 343 \\
$\mathrm{Cu}$ & 26.0 & 12.4 & 14 & 6.4 & 352 \\
$\mathrm{~V}$ & 16.6 & 7.4 & 15.5 & 6.4 & 348 \\
$\mathrm{Hf}$ & 16.5 & 7.2 & 15.9 & 6.3 & 345 \\
$\mathrm{Mo}$ & 13.5 & 6.6 & 14.9 & 6.5 & 343 \\
$\mathrm{Cr}$ & 34.5 & 14.7 & 15.2 & 6.2 & 354 \\
$\mathrm{Ti}$ & 36.4 & 5.5 & 15.5 & 6.7 & 354 \\
\hline
\end{tabular}

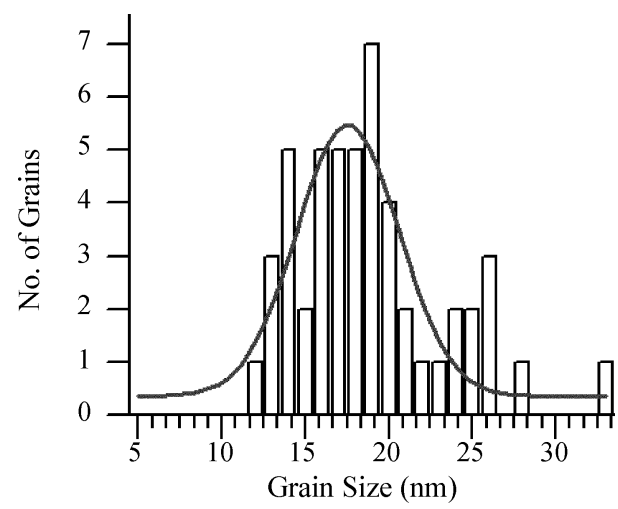

Fig. 2. Grain size histogram and Gaussian fit for $\operatorname{Pr}_{9}\left(\mathrm{Fe}_{0.95} \mathrm{Co}_{0.05}\right)_{85.5} \mathrm{~B}_{5}$ obtained from an analysis of Fig. 1(a). This curve is typical of all the samples analyzed.
In general, the grain size was not reduced significantly upon the addition of $\mathrm{M}$, with the exception of $\mathrm{M}=$ Mo. However, some additions had a detrimental effect on the grain size, notably $\mathrm{Cu}, \mathrm{Ti}$, and $\mathrm{Cr}$. $\mathrm{Cu}$ and $\mathrm{Cr}$ are very close in size to $\mathrm{Fe}$, and thus likely are soluble in either the 2-14-1 phase or $\alpha$-Fe. This solubility in turn could alter the nucleation and growth characteristics, resulting in increased grain size. The Group VB transition metals $(\mathrm{V}, \mathrm{Nb})$ were generally more effective in maintaining/refining the grain size than Group IVB transition metal substitutions (Ti, Zr, Hf) and other additions. With negligible grain refinement occurring upon the addition of $\mathrm{M}$, it is presumed that segregation of $\mathrm{M}$ to grain boundaries is not likely, as then one would expect a grain boundary drag effect and a refinement in grain size. The exception might be $\mathrm{M}=\mathrm{Mo}$, which had a reduced grain size. It also had a lower energy product, which could be explained by Mo at grain boundaries acting to de-couple the grains.

The variation in microstructure in specific instances strongly affected the magnetic properties. For example, the larger grain size of the sample with $\mathrm{M}=\mathrm{Cu}$ led to a loss in hysteretic squareness, leading to reduced energy product (Fig. 3). However, in general we did not see a correlation between grain size and energy product (Fig. 4). This is surprising, and may arise from a number of factors. First of all, the alloying addition may segregate to grain boundaries, reducing grain size but also acting to de-couple grains [8]. The alloying element may also substitute at least partially in either the 2-14-1 or $\alpha$-Fe structures, thereby altering intrinsic properties. A dependence of Curie temperature on the size of $\mathrm{M}$ was observed, suggesting substitutional affects do influence the magnetic behavior. Finally, the alloying addition may preferentially affect the grain size or structure of one of the two phases, resulting in, for 


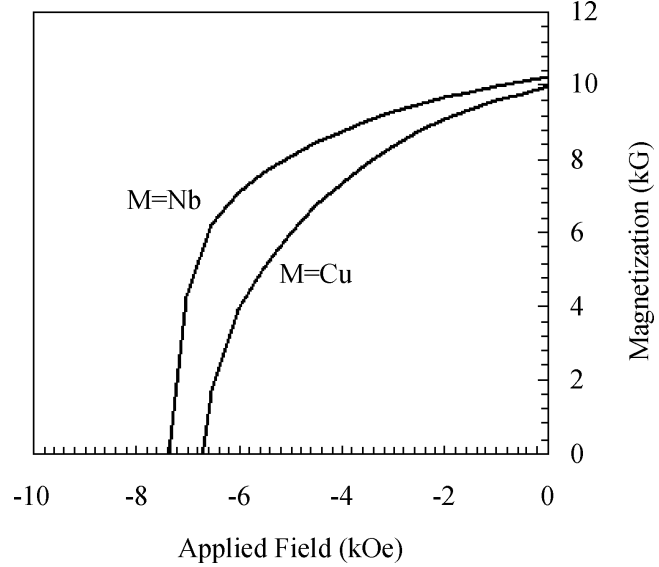

Fig. 3. Demagnetization curves for $\operatorname{Pr}_{9}\left(\mathrm{Fe}_{0.95} \mathrm{Co}_{0.05}\right)_{85.5} \mathrm{M}_{0.5} \mathrm{~B}_{5}$ with $M=N b$ and $\mathrm{Cu}$ illustrating the effects of grain size and grain distribution on the magnetic properties.

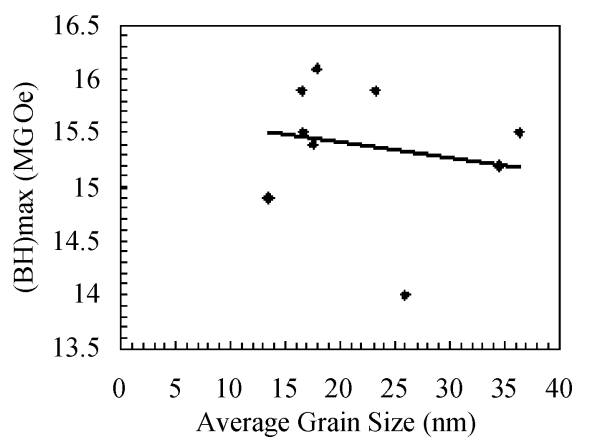

Fig. 4. Maximum energy product as a function of grain size for the $\operatorname{Pr}_{9}\left(\mathrm{Fe}_{0.95} \mathrm{Co}_{0.05}\right)_{85.5} \mathrm{M}_{0.5} \mathrm{~B}_{5}$ alloys.

example, a more refined $\alpha$-Fe phase, enhancing the exchange coupling. These effects are difficult to sort out, but further work is on-going to attempt to illuminate the net effect of the allowing additions on microstructure and magnetic properties.

\section{CONCLUSION}

The microstructures of $\mathrm{Pr}-\mathrm{Fe}-\mathrm{B}$-based nanocomposite permanent magnets have been quantified with respect to the effect of various transition metal alloying additions on the grain size and grain size distribution. Very little reduction in grain size was observed for any of the alloying additions. However, in some cases grain size increased upon alloying, notably for additions of $\mathrm{Cu}, \mathrm{Cr}$, and Ti. Transition metal additions from other rows in the periodic table were overall more beneficial with respect to the microstructure and magnetic behavior. Group VB additions were found to have the most positive effect on the microstructure and magnetic properties.

\section{REFERENCES}

[1] Z. M. Chen, Y. Zhang, Y. Q. Ding, G. C. Hadjipanayis, Q. Chen, and B. M. Ma, "Studies on magnetic properties and microstructure of melt-spun nanocomposite $\mathrm{R}_{8}(\mathrm{Fe}, \mathrm{Co}, \mathrm{Nb})_{86} \mathrm{~B}_{6}(\mathrm{R}=\mathrm{Nd}, \mathrm{Pr})$ magnets," J. Magn. Magn., vol. 195, pp. 420-426, 1999.

[2] presented at the Proc. 13th Int. Workshop on Rare Earth Magnets and Their Applications, 1994, p. 79.

[3] J. Bernardi, T. Schrefl, J. Fidler, T. Rijks, K. deDort, V. Archambault, D. Pere, S. David, D. Givord, J. F. O'Sullivan, P. A. I. Smith, J. M. D. Coey, U. Czernik, and M. Gronefeld, "Preparation, magnetic properties, and microstructure of lean rare-earth permanent magnetic materials," $J$. Magn. Magn. Mater, vol. 219, p. 186, 2000.

[4] W. C. Chang, S. H. Wu, B. M. Ma, and C. O. Bounds, "The effects of La-substitution on the microstructure and magnetic properties of nanocomposite NdFeB melt spun ribbons," J. Magn. Magn. Mater., vol. 167 , p. $65,1997$.

[5] K. H. J. Buschow, Handbook of Magnetic Materials, K. H. J. Buschow, Ed. Amsterdam, The Netherlands: Elsevier, 1997, vol. 10, p. 463.

[6] J. E. Shield and B. E. Meacham, "Phase formation in hypostoichiometric Sm-Fe alloys modified with Ti and C," J. Appl. Phys., vol. 87, p. 2055, 2000.

[7] J. E. Shield, "Phase formation and crystallization behavior of Sm-Febased alloys," J. Alloys Compounds, vol. 291, p. 222, 1999.

[8] J. E. Shield, B. B. Kappes, D. J. Branagan, and J. Bentley, "Microstructural development and chemical partitioning during crystallization of modified Nd-Fe-B permanent magnets," J. Magn. Magn. Mater, vol. 246, pp. 85-91, 2002. 